\title{
ELECTRIC INTENSITY DISTRIBUTION OF CROSS-LINKED POLYETHYLENE BASED HIGH-VOLTAGE CABLE TERMINATION
}

\author{
Yong Luo', Dingke Chen", Chun Chen ${ }^{3}$ \\ 1,2,3 State Grid Chongqing Beibei Power Supply Company, Chongqing, 400700, China \\ dingkchen@aliyun.com
}

\begin{abstract}
Cross-linked polyethylene (XLPE) based high-voltage cable termination has extremely uneven distribution of electric intensity distribution, which limits its development. This study explored the influence of different insulating materials of XLPE based high-voltage cable termination on electric intensity. A simulation model of high-voltage cable termination was established using a multi-physics coupling simulation software. Ordinary silicone rubber and nanographite-silicone rubber composite were taken as the reinforced insulation of termination. The simulation results showed that the farther away from the root of the stress cone, the smaller the field strength. When ordinary silicone rubber was used as the reinforced insulation, the high electric field concentrated at the root of the stress cone, and the maximum electric field strength was $88.67 \mathrm{kV} / \mathrm{mm}$. When nano-graphite-silicone rubber composite was used as reinforcing insulation, high electric field uniformly distributed in the XLPE insulation of cable terminal, the maximum electric field was $14.79 \mathrm{kV} / \mathrm{mm}$, and the electric field strength at the root of stress cone was about one tenth of that of ordinary silicone rubber. It indicates that nano-graphite-silicone rubber composite can homogenize the electric field distribution and reduce the possibility of breakdown damage of termination and is a suitable reinforced insulation for high-voltage cable termination.
\end{abstract}

Keywords: Cross-linked Polyethylene, Cable Termination, Electric Field Intensity, Silicone Rubber, Nano-Graphite.

\section{Introduction}

Cross-linked polyethylene (XLPE) based high voltage cable has been more and more widely used in the power industry because of its superior properties [1]. Compared with the cable itself, it is more difficult to make the cable terminal, and cable terminal has a great impact on the overall operation of the cable. Cable terminal is the weak part of high voltage cable. Improving the design of cable terminal plays an important role in improving the overall properties of cable [2]. The electric field distribution in the terminal can be controlled by optimizing the size of the stress cone [3] and using the stress control tube [4]. It is found that the selection of reinforced insulating materials in cable terminal will directly affect the distribution of field strength in terminals [5]. Han et al. [6] calculated the electric field distribution of High Voltage Direct Current cable terminal and found that the electric field distortion of the terminal was serious and the maximum electric field intensity was 6.7 times of the average electric field intensity in the cable when ordinary silicone rubber was used as insulating material. Wang et al. [7] developed a compound material with nano-SiC and silicone rubber, studied its electrical conductivity and breakdown strength, and found that the composite material could effectively homogenize electric field and reduce the maximum field intensity value. Song et al. [8] studied silicone rubber nanocomposite and found that changing the proportion of nanofiller could control the physical parameters of nanocomposite and make the maximum field intensity appear in insulating body. Through simulation experiments, Hou et al. [9] found that the use of non-linear conductive silicone rubber as the reinforced insulation of terminal could make the distribution of electric field uniform and improve the properties of cables. In this study, ordinary silicone rubber and nano-graphite-silicone rubber were used as terminal reinforcement insulation. A simulation model was established by simulation software, and the electric field intensity distribution was calculated to understand the influence of different materials on the electric field intensity distribution.

\section{XLPE High-Voltage Cable}

Cable is an indispensable part of power transmission. It not only saves land resources, but also can transmit power in various environments. It has high security and concealment. High-voltage cable has high application value in long-distance 
transmission [10]. Traditional high-voltage cables use oil-filled cables or impregnated paper insulated cables, which are gradually replaced by XLPE cables because of their high cost, complex fabrication and difficult maintenance.

Polyethylene material is easy to deform at high temperature. The crosslinking process can make it maintain good deformation resistance at high temperature. It also has excellent heat resistance, acid and alkali resistance and oil resistance. It will not produce toxic gases but water and carbon dioxide after combustion, which will not cause great pollution [11].

Compared with traditional high-voltage cables, XLPE high-voltage cables have smaller losses, larger transmission capacity and longer service life in the process of transmission, which have been widely recognized and used in the power industry. Its basic structure is shown in Figure 1.

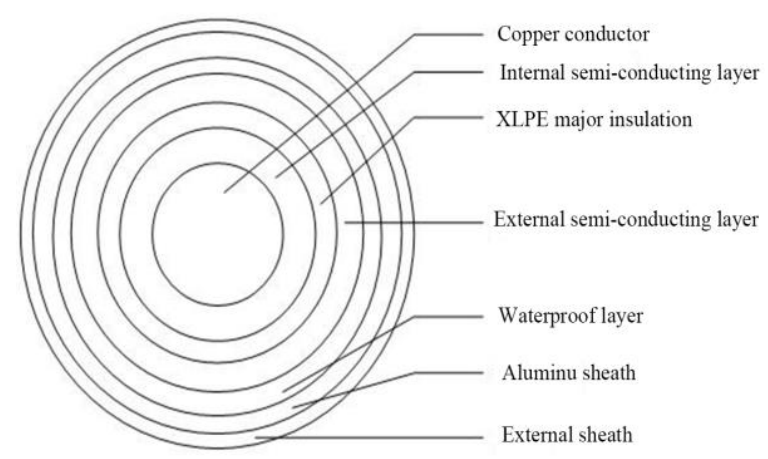

Figure 1: The XLPE single-cored copper conductor cable

Cable terminal is a weak part of high-voltage cable. Its properties has a great influence on the overall operation of cables. Cable terminal is easy to have electric field distortion and uneven distribution of electric field, which is one of the main causes for cable failure.

\section{Simulation Model of XLPE High Voltage Cable Terminal}

A simulation model as shown in Figure 2 was established using multi-physics coupling simulation software and $\pm 200 \mathrm{kV}$ XLPE high-voltage cable.

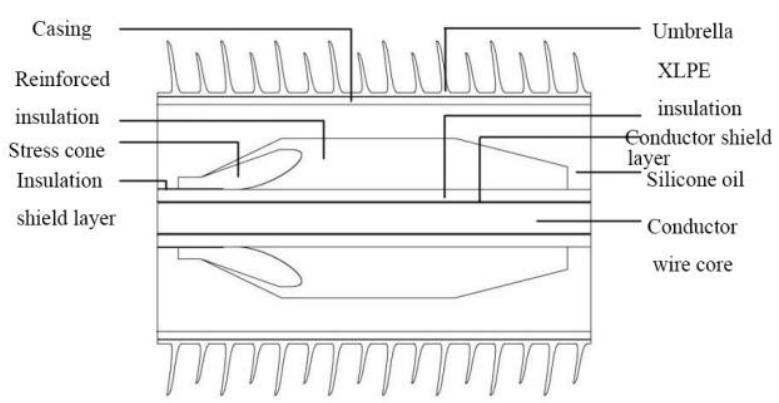

Figure 2: The structure of XLPE cable terminal

Insulation material will affect the distribution of electric field in insulation layer. The volume conductivity of insulation material is correlated to electric field and temperature, and the expression is:

$$
\gamma(E, t)=\gamma_{0} \exp (\alpha t+\beta E)
$$

where ${ }^{\gamma}$ stands for conductivity (S/m), $\gamma_{0}$ stands for conductivity under $0{ }^{\circ} \mathrm{C}$ and $0 \mathrm{KV} / \mathrm{mm}, \alpha$ stands for temperature coefficient $\left(1 /{ }^{\circ} \mathrm{C}\right), t$ stands for temperature $\left({ }^{\circ} \mathrm{C}\right), \quad \beta$ stands for electric field intensity coefficient $(\mathrm{m} / \mathrm{V})$, and $E$ stands for field intensity $(\mathrm{V} / \mathrm{m})$.

The conductivity of insulation material of stress cone of cable terminal is:

$$
\gamma(E, t)=\gamma_{1} \exp \left(\alpha_{1} t+\beta_{1} E\right)
$$

The conductivity of insulating oil is:

$$
\gamma(E)=\gamma_{2} \exp \left(\beta_{2} E\right)
$$

The conductivity of the other materials is constant.

Table 1 Simulation parameters

\begin{tabular}{|l|l|l|l|l|l|l|l|}
\hline Parameters & Copper & XLPE & $\begin{array}{l}\text { Semiconductive } \\
\text { material }\end{array}$ & $\begin{array}{l}\text { Ordinary } \\
\text { silicone } \\
\text { rubber }\end{array}$ & $\begin{array}{l}\text { Nano-graphite- } \\
\text { silicone rubber }\end{array}$ & Silicone oil & Ceramics \\
\hline $\begin{array}{l}\text { Heat } \\
\text { conductivity } \\
(\mathrm{W} / \mathrm{m} \cdot \mathrm{k})\end{array}$ & 385 & 0.33 & 0.29 & 0.25 & 0.38 & 0.12 & 2.00 \\
\hline $\begin{array}{l}\text { Electrical } \\
\text { conductivity } \\
(\mathrm{S} / \mathrm{m})\end{array}$ & $5.9 \times 107$ & - & 10 & - & - & $10-14$ & $10-12$ \\
\hline Density $(\mathrm{kg} / \mathrm{m} 3)$ & 8900 & 910 & 1100 & 1150 & 1275 & 970 & 3650 \\
\hline
\end{tabular}

Different physical properties of the simulation model were set according to the parameters. Data were processed using solver of simulation software to obtain the electric field distribution of cable terminal.
The changes of conductivity of the three kinds of materials under $30^{\circ} \mathrm{C}$ and $70^{\circ} \mathrm{C}$ were fitted according to the above formulas, and the results are shown in Figure 3. 


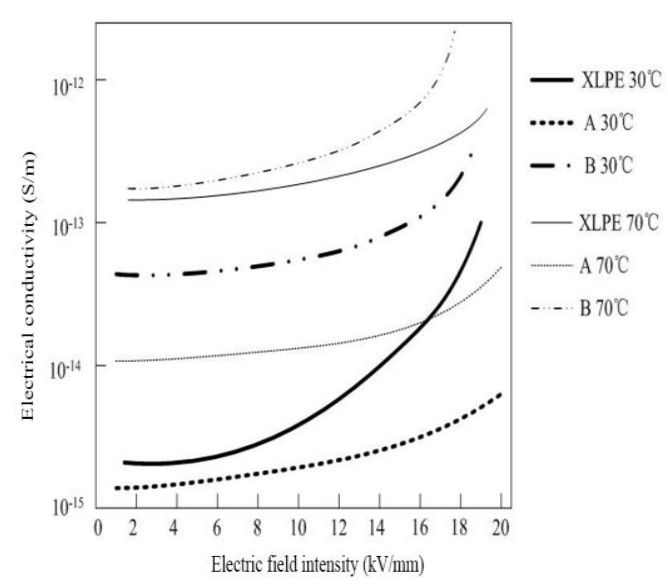

Figure 3: The conductivity of different materials with the changes of field intensity under different temperatures

It was found from Figure 3 that the conductivity of ordinary silicone rubber material (A) varied smoothly, while that of nano graphite-silicone rubber composite (B) and XLPE varied greatly and increased with the increase of temperature and field strength. Under the same temperature, the conductivity of nano-graphite-silicone rubber composite (B) was higher than that of XLPE. The conductivity of nano-graphite-silicone rubber composite (B) was about 10-20 times that of XLPE under $30{ }^{\circ} \mathrm{C}$ and $10 \mathrm{kV} / \mathrm{mm}$. The conductivity of nano-graphite-silicone rubber composite (B) was about 3 times that of XLPE at $70{ }^{\circ} \mathrm{C}$ and $10 \mathrm{kV} / \mathrm{mm}$.

\section{Results of Electric Field Intensity Distribution of XLPE High-Voltage Cable Terminal}

The electric field intensity of cable terminal is mainly affected by the conductivity of insulation material. The electric field intensity distribution of ordinary silicone rubber cable terminal and nanographite-silicone rubber cable terminal were simulated and analyzed. (2), (3) and (4) and the other simulation parameters were substituted into the simulation software. The voltage of cable core was $200 \mathrm{kV}$, and the temperature was $40^{\circ} \mathrm{C}$.

\section{Comparison of nephogram of electric field distribution of cable terminal}

The nephogram of electric field distribution of the ordinary silicone rubber cable terminal and nano-graphite-silicone rubber cable terminal is shown in Figure 4 and 5.

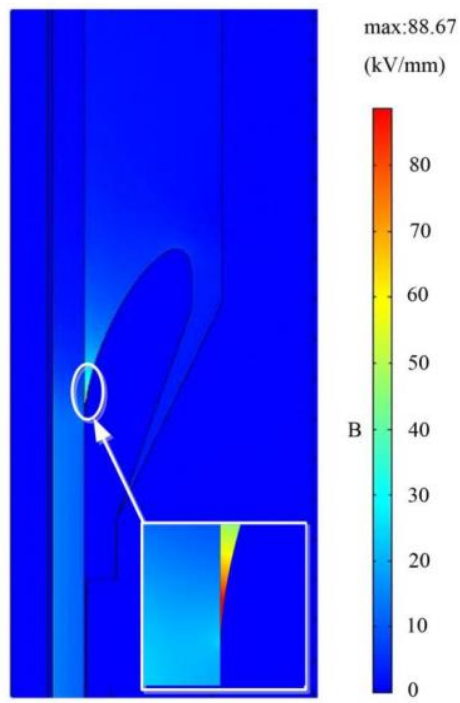

Figure 4: Ordinary silicone rubber

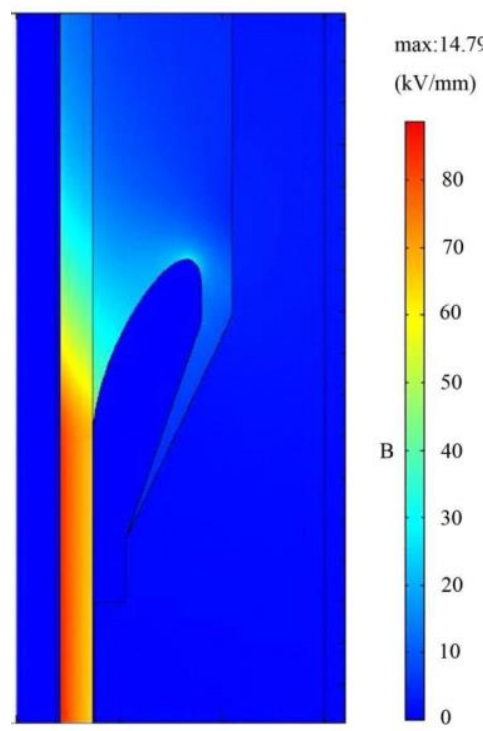

Figure 5: Nano-graphite-silicon rubber composite

Figure 4 is the electric field distribution nephogram of the ordinary silicone rubber terminal. It was found that the maximum electric field of the cable terminal was $88.67 \mathrm{kV} / \mathrm{mm}$ in the reinforced insulation near the root of the stress cone and the electric field distribution was unreasonable. Figure 5 is the electric field intensity distribution nephogram of the nano-graphite-silicone rubber composite cable terminal. It was found that the maximum electric field strength was $14.79 \mathrm{kV} / \mathrm{mm}$, which was significantly lower than $88.67 \mathrm{kV} / \mathrm{mm}$ of the ordinary silicone rubber cable terminal. The position with high electric field was concentrated in the XLPE insulation of the body at the root of the stress cone. Breakdown failure is easy to occur when high field strength is concentrated in reinforced insulation. It indicated that ordinary silicone rubber as reinforced insulation was likely to cause cable damage. 


\section{Comparison of electric field intensity near stress cone}

Table 2 Comparison of electric field intensity near the stress cone

\begin{tabular}{|l|l|l|l|l|}
\hline \multirow{2}{*}{$\begin{array}{l}\text { Distance with } \\
\text { the root of } \\
\text { stress cone }\end{array}$} & \multicolumn{2}{|l|}{$\begin{array}{l}\text { Electric field intensity of } \\
\text { insulation interface }(\mathrm{kV} / \mathrm{mm})\end{array}$} & \multicolumn{2}{|l|}{$\begin{array}{l}\text { Electric field intensity on the } \\
\text { surface of stress cone }(\mathrm{kV} / \mathrm{mm})\end{array}$} \\
\cline { 2 - 5 } & $\begin{array}{l}\text { Ordinary } \\
\text { Silicone } \\
\text { rubber }\end{array}$ & Composite & $\begin{array}{l}\text { Ordinary } \\
\text { silicone } \\
\text { rubber }\end{array}$ & Composite \\
\hline 0 & 88.67 & 8.56 & 88.67 & 8.21 \\
\hline 10 & 67.42 & 7.83 & 42.31 & 7.56 \\
\hline 20 & 59.84 & 6.92 & 26.35 & 6.83 \\
\hline 50 & 17.63 & 5.18 & 9.67 & 4.07 \\
\hline 100 & 9.27 & 4.21 & 8.42 & 4.91 \\
\hline 200 & 6.32 & 2.16 & 7.62 & 3.21 \\
\hline 300 & 3.18 & 1.08 & 7.54 & 2.67 \\
\hline
\end{tabular}

The general trend of the electric field strength of the two materials was that the farther away from the root of the stress cone, the smaller the electric field strength. However, the electric field strength at the root of the stress cone of ordinary silicone rubber was much higher than that of the composite material whether the electric field strength was on the insulation interface or on the surface of stress cone.

When nano-graphite-silicone rubber composite was used as reinforced insulation, the electric field modulus of the insulation interface was only about
$8.5 \mathrm{kV} / \mathrm{mm}$, and the electric field modulus of the stress cone was only about $8.4 \mathrm{kV} / \mathrm{mm}$, which was about one tenth of that of the ordinary silicone rubber cable terminal. It indicated that nanographite-silicone rubber composite could make the electric field distribution more uniform and concentrate the high electric field area in insulating body, which effectively reduced the possibility of terminal breakdown failure.

\section{Comparison of electric field distribution under different voltages}

\begin{tabular}{|l|l|l|l|l|}
\hline \multicolumn{2}{|c}{} & \multicolumn{2}{l}{ Table 3 Comparison of field intensity } \\
Reinforced insulation & Ordinary silicone rubber & \multicolumn{2}{l|}{$\begin{array}{l}\text { Nano-graphite-silicon } \\
\text { rubber composite }\end{array}$} \\
\hline Cable voltage $(\mathrm{kV})$ & 290 & 370 & 290 & 370 \\
\hline $\begin{array}{l}\text { Maximum field intensity } \\
(\mathrm{kV} / \mathrm{mm})\end{array}$ & 112.34 & 135.69 & 13.27 & 14.72 \\
\hline $\begin{array}{l}\text { Average field intensity } \\
(\mathrm{kV} / \mathrm{mm})\end{array}$ & 17.68 & 22.39 & 17.68 & 22.39 \\
\hline High field intensity area & $\begin{array}{l}\text { Ordinary silicone } \\
\text { rubber }\end{array}$ & $\begin{array}{l}\text { Ordinary silicone } \\
\text { rubber }\end{array}$ & XLPE & XLPE \\
\hline
\end{tabular}

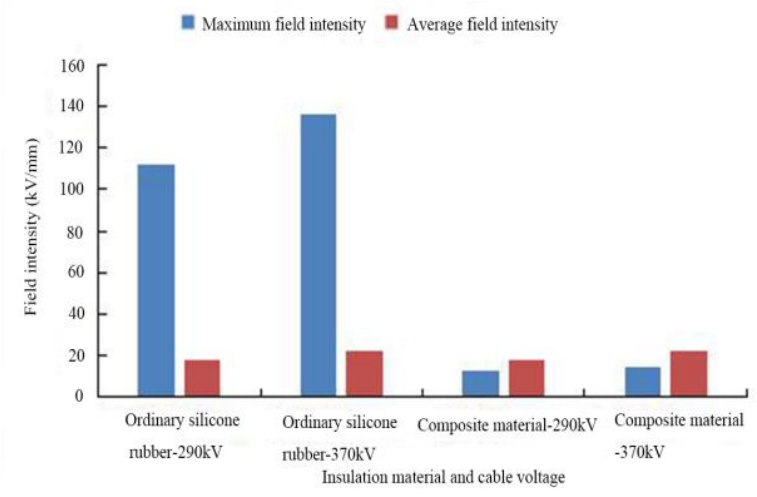

Figure 6: Comparison of field intensity distribution
Table 2 and Figure 6 show the comparison of electric field distribution in cable terminal when two kinds of materials were used as reinforced insulation at 290 and $370 \mathrm{kV}$. It was found that the average electric field strength in the terminal was the same for different materials under the same voltage, which indicated that adding nano-graphite in silicone rubber would not enhance the average electric field strength of the cable terminal. When ordinary silicone rubber was used as insulating material, the maximum field intensity in the terminal was far higher than the average field intensity, and the high field intensity area always concentrated in the reinforced insulation. The maximum field intensity 
in the terminal which used composite material as the reinforced insulation was far smaller than that in the ordinary silicone rubber cable terminal, close to the average field intensity, and the high field intensity area always concentrated in the XLPE insulation of the body. The comparison shown in Figure 6 suggested that the maximum field intensity in the terminal which used ordinary silicone rubber as the reinforced insulation was about ten times that in the terminal which used composite material. Ordinary silicone rubber not only has extremely large maximum field intensity, but also has high field intensity area concentrated in the reinforced insulation; hence it is prone to breakdown failure.

\section{Discussion}

XLPE high voltage cable has been widely used in power transmission [12]. The properties of high voltage cable terminal has a great influence on the operation of cable. Most cable faults are caused by defects of cable terminals or joints [13]. Due to the uneven distribution of electric field at cable terminal, the insulation of terminal is prone to breakdown, which can lead to the insulation damage of highvoltage cables and seriously affect the practicability of high-voltage cables. In order to make the distribution of terminal electric field more uniform, the traditional method is to control the distribution of electric field by adding shielding metal and embedding capacitor plate [14]; but in this way, cable manufacturing becomes more difficult, and the result is not ideal. It is found that the material of reinforced insulation of cable terminal has a great influence on the electric field distribution of terminals. The distribution of electric field is different when different insulating materials are used as reinforced insulation.

In this study, the electrical conductivity of XLPE insulating materials, ordinary silicone rubber and nano graphite-silicone rubber composites were calculated and compared. The electrical conductivity of XLPE varied greatly with temperature and electric field, while that of ordinary silicone rubber varied little. It showed that the conductivity of XLPE was much higher than that of silicone rubber during the operation of high voltage cable, which would make the electric field distribution inside the cable terminal uneven and cause breakdown failure. Compared with ordinary silicone rubber, the electrical conductivity of nano-graphite-silicone rubber composite changed as much as XLPE and was higher than that of XLPE. At $70^{\circ} \mathrm{C}$, the electrical conductivity of the composite was always higher than that of XLPE; hence the high field intensity area was always be in the XLPE insulation. It indicated that the performance of nano-graphite-silicone rubber composite was superior to that of ordinary silicone rubber as reinforced insulation.
In order to further understand the electric field distribution of these two materials when they are used as terminal reinforced insulation, a simulation model of high voltage cable was established by using multi-physics field coupling simulation software. The simulation results suggested that the maximum electric field intensity of the terminal reached 88.67 $\mathrm{kV} / \mathrm{mm}$ when ordinary silicone rubber was used as reinforced insulation. The electric field distribution nephogram showed that the high electric field area concentrated in the silicone rubber reinforced insulation near the root of stress cone, which was much larger than the field intensity of XLPE insulation of the body. The closer to the root of stress cone, the greater the electric field intensity and the higher the electric field intensity; high field intensity near the root of stress cone may cause partial discharge and affect the operation of cable [15]. It was found that the electric field distribution of the terminal was not uniform when ordinary silicone rubber was used as reinforced insulation, and it was prone to discharge or breakdown failure; therefore it is not suitable as the reinforced insulation of highvoltage cable terminal.

The simulation results of nano-graphite-silicone rubber composite showed that the maximum field intensity in the terminal was only $14.79 \mathrm{kV} / \mathrm{mm}$ when the material was used as the terminal reinforced insulation. It was found from the electric field distribution nephogram that the overall distribution was uniform, and the high electric field was uniformly distributed in the XLPE insulation. It was found from Figure 8 and 9 that the field intensity at the root of the stress cone was between 8 and $9 \mathrm{kV} / \mathrm{mm}$, which was about one tenth of the ordinary silicone rubber as the terminal reinforced insulation. It showed that the composite material could be used as reinforced insulation to concentrate the high electric field area in the insulating body, protect the terminal insulation, reduce the possibility of breakdown damage, and effectively improve the practicability of high voltage cable.

\section{Conclusion}

In this study, the electric field intensity distribution of XLPE high voltage cable terminal was studied. By establishing the simulation model of high-voltage cable terminal using the multi-physics field coupling simulation software, the influence of two kinds of terminal reinforced insulating materials, ordinary silicone rubber and nano-graphite-silicone rubber composite, on the electric field distribution was calculated. The results showed that the electric field distribution of terminal reinforced insulating material which used ordinary silicone rubber as reinforced insulation was uneven and high field intensity area was concentrated in the reinforced insulation. When nano-graphite-silicone rubber composite was used as reinforced insulation, the 
distribution of field intensity was even and high field intensity area was concentrated in the XLPE insulation of the body, which could effectively reduce the possibility of cable failure and improve the practicability of cables. Nano-graphite-silicone rubber composite is more suitable as terminal reinforced insulation.

\section{References}

[1] Duan Y, Hu XL, Zhang H, et al. "High-frequency Current Detection on Partial Discharge and X-ray Detection On-line Detection of XLPE High-voltage Cable." Shandong Electric Power, 2016.43(9):1014.

[2] Wong J K, Illias $\mathrm{H}$ A, Mokhlis $\mathrm{H}$, et al. "Investigation of partial discharge severity at XLPE cable without termination." IEEE International Conference on Power and Energy. IEEE, 2015:13-16.

[3] Miao R Z, Wu S F, Li W Q. "Size Optimizations to the Stress Cones in $48 \mathrm{kV}$ XLPE Cable Terminations." Power and Energy Engineering Conference. IEEE, 2012:1-4.

[4] Kucheriava I M. "Electric field distribution in medium-voltage xlpe cable termination taking into account outer semiconducting layer." Technical Electrodynamics, 2016(3):12.

[5] llias H A, Ng Q L, Bakar A H A, et al. "Electric field distribution in $132 \mathrm{kV}$ XLPE cable termination model from finite element method." International Conference on Condition Monitoring and Diagnosis. IEEE, 2012:80-83.

[6] Han B, Fu ML, Li CY, et al. "Effect of Silicone Rubber's Electric Conductance Characteristic on Electric Field Distribution Inside XLPE Insulated HVDC Cable Termination." High Voltage Engineering, 2014, 40(9):2627-2634.

[7] Wang F F, Zhang P H, Gao M Z. "Research on the nonlinear conductivity characteristics of nanoSiC/silicone rubber composites." Acta Physica Sinica, 2014, 63(21):435-538.
[8] Song S W, Li Z, Zhao H, et al. "Electric field control in DC cable test termination by nano silicone rubber composite." Aip Advances, 2017, 7(7):1015.

[9] Hou S, Fu M, Li C, et al. "Electric field calculation and analysis of HVDC cable joints with nonlinear materials. Properties and Applications of Dielectric Materials." IEEE, 2015:184-187.

[10] Lee S B, Lee T H, Jung E H, et al. "Development of 250kV HVDC XLPE cable system in Korea." International Symposium on Electrical Insulating Materials. IEEE, 2014:334-337.

[11] Hedlund B. "XLPE-cable Production Optimization - Setup time Reduction at Armoring line." Die Makromolekulare Chemie Rapid Communications, 2014, 13(1):1-7.

[12] Malik N H, Al-Arainy A A, Qureshi M I, et al. "Calculation of electric field distribution at high voltage cable terminations. International Conference on High Voltage Engineering and Application." IEEE, 2010:24-27.

[13] Raicevic N B, Aleksic S R, Ilic S S. "One numerical method to determine improved cable terminations." Electric Power Systems Research, 2011, 81(4):942-948.

[14] Dimitrijevic R M, Tasic D S, Raicevic N B, et al. "Analysis of a MV XLPE Cable Termination Design with Embedded Electrodes." Facta universitatis series: Electronics and Energetics, 2010, 23(1):99-117.

[15] Bhattacharyya S, Chakraborty A, Saha B, et al. "Electric stress analysis of a medium voltage cable termination subjected to standard and nonstandard lightning impulse voltages." International Conference on Intelligent Control Power and Instrumentation. I. 